\title{
Magnesium Isoglycyrrhizinate Suppresses the Progression of Bladder Cancer by Modulating miR- 26b/Nox4 Axis
}

\section{Zhihao Yuan}

zhengzhou university

\section{Guancheng Guo}

zhengzhou university

Guifang Sun

zhengzhou university

Qi Li

zhengzhou university

\section{Lihui Wang}

zehngzhou university

\section{Baoping Qiao ( $\triangle$ BaopingQiaoHenan@163.com )}

The First Affiliated Hospital of Zhengzhou University

\section{Research article}

Keywords: Magnesium Isoglycyrrhizinate, bladder cancer, miR-26b, Nox4/ NF-kB/HIF-1a, apoptosis

Posted Date: September 21st, 2020

DOI: https://doi.org/10.21203/rs.3.rs-52130/v1

License: (1) This work is licensed under a Creative Commons Attribution 4.0 International License.

Read Full License

Version of Record: A version of this preprint was published at Bioengineered on March 16th, 2022. See the published version at https://doi.org/10.1080/21655979.2022.2031677. 


\section{Abstract}

Background: Magnesium Isoglycyrrhizinate (MI), a magnesium salt of 18a-GA stereoisomer, has been reported to exert efficient hepatoprotective activity. However, its effect in bladder cancer remain unclear.

Methods: The effect of $\mathrm{MI}$ in the growth, colony formation, apoptosis, invasion and migration of bladder cancer cells (HTB9 and BIU87 cells) was evaluated in vitro. Typical apoptotic changes of bladder cancer cells such as nuclear concentration and fragmentation was observed by Hoechst staining. The effect of $\mathrm{Ml}$ in the expression of miR-26b, Nox4, NF-KB and HIF-1 a was detected by qRT-PCR and western blot in vitro. Targetscan was used to predict the potential targets of miR-26b, then their interaction was determined by the luciferase reporter assay. Finally, the xenograft model of mice was established to evaluate the anti-tumor effects of $\mathrm{Ml}$ in vivo.

Results: MI significantly suppressed the proliferation, colony formation, invasion, migration and induced apoptosis of human bladder cancer cells. Nox4 was identified to be a direct target of miR-26b, and MI significantly increased the expression of miR-26b. MiR-26b mimics significantly decreased the relative luciferase activity of wild type (WT) Nox4, while exhibited no obvious change in mutant type (MUT) Nox4. Meanwhile, MI markedly downregulated the expression of Nox4, NF-KB and HIF-1a both in vitro and in vivo. Moreover, $\mathrm{Ml}$ could efficiently inhibit the growth of xenograft tumor in vivo, and also obviously decreased the expression of Nox4, NF-KB and HIF-1a.

Conclusion: In summary, MI showed a potent anti-tumor effect against bladder cancer partially through modulating miR-26b/Nox4 axis.

\section{Background}

Bladder cancer has becoming a common cancer worldwide with higher morbidity and mortality, and also with an estimated 430000 new cases diagnosed every year ${ }^{1,2}$. The incidence of bladder cancer is higher in old men than young, suggesting the geographic variation and is mostly an environmental disease ${ }^{3}$. Even worse, there are approximately one-third of patients with muscle-invasive bladder cancer already have undetected metastases at the time of treatment ${ }^{4}$. Although considerable progress has been achieved in surgical techniques and adjuvant chemotherapies, the mortality of bladder cancer is still higher ${ }^{5}$. A large number of previous studies have demonstrated that the occurrence and development of bladder cancer is a complex process, which can be caused by abnormal genetic changes or epigenetic abnormalities ${ }^{6}$. Therefore, a better understanding of specific mechanism in the progression of bladder cancer contributes to identify efficient drug targets and even expends the window period of treatment in bladder cancer.

Magnesium isoglycyrrhizinate (MI), a magnesium salt of 18a-GA stereoisomer, has been known as an efficient hepatoprotective agent ${ }^{7-9}$. Expect for protective effect on the liver, MI has been identified to exert potential protective effect in various human diseases. For instance, MI can prevent drug-induced liver 
damage after the initial chemotherapy for those patients with early stage gastrointestinal cancer ${ }^{10}$. One previous study reported that the liver toxicities induced by paclitaxel plus cisplatin chemotherapy can potentially decrease the ability of hepatic elimination and increase system exposure of paclitaxel, while $\mathrm{Ml}$ efficiently help to restore hepatic clearance of paclitaxel ${ }^{11}$. MI can protect against renal-ischemia-reperfusion injury in a rat model through anti-inflammation, anti-oxidation and anti-apoptosis capacity ${ }^{12}$. MI has been demonstrated to inhibit the myocardial hypertrophy by inactivating the TLR4/NF-KB signaling pathway in mice ${ }^{13}$. In addition, MI has also reported that can ameliorate fructose-induced podocyte apoptosis by downregulating the expression of miR-193a to upregulate Wilms' tumor protein (WT1) expression ${ }^{14}$. However, the effect of MI in bladder cancer has not been studied.

MicroRNAs (miRNAs) are a group of small and non-coding RNAs with approximately 22 nucleotides in length, and often regulate gene expression post-transcriptionally though binding to the 3 '-untranslated region ( $3^{\prime}-U T R$ ) of the target mRNAs ${ }^{15}$. Recently, miR-26b has been a focus of interest for its role as a tumor suppressor in several cancer types. In colorectal cancer, upregulation of miR-26b promotes chemosensitivity of cancer cells through targeting P-glycoprotein (Pgp ${ }^{16}$. In esophageal squamous cancer, miR$26 \mathrm{~b}$ can inhibit the cell proliferation by suppressing c-MYC signaling pathway, and suggested that miR$26 \mathrm{~b}$ might be a potential target of prevention and treatment of esophageal squamous cancer ${ }^{17}$. In lung cancer, miR-26b has been identified that can inhibit the invasion and migration of cancer cells by directly targeting hENT1 depending on RhoA/ROCK-1 signaling pathway ${ }^{18}$. Although previous studies have revealed the crucial anti-tumor effect in various cancers, its function in bladder cancer remains unclear.

$\mathrm{NAD}(\mathrm{P}) \mathrm{H}$ oxidase 4 (Nox4), a substrate of NADPH that can generate $\mathrm{H}_{2} \mathrm{O}_{2}$ reactive oxygen species, has been reported to be highly expressed in human tumors ${ }^{19}$. NOX4 can support glycolysis and promote glutamine metabolism in non-small cell lung cancer (NSCLC) cells ${ }^{20}$. NOX4-driven ROS formation has been found to regulate the proliferation and apoptosis of gastric cancer cells via the GLI1 pathway ${ }^{21}$. In addition, Nox4 has been identified to be closely correlated with gastric cancer progression and predicts a poor prognosis ${ }^{22}$. Although Nox4 also play essential roles in the development of bladder cancer ${ }^{23}$, the regulatory axis of Nox4 in bladder cancer has not been well studied.

In this study, we explore the role and molecular mechanisms of MI in bladder cancer, and firstly reported that $\mathrm{MI}$ could efficiently inhibit the progression of bladder cancer both in vitro and in vivo, specifically, MI could suppress the activation of Nox4/ NF-KB/HIF-1a signaling pathway through upregulating the expression of miR-26b. Our results indicated that MI might a potential anti-tumor agent against bladder cancer.

\section{Methods}

\section{Materials}


Magnesium isoglycyrrhizinate (MI) (purity $>98 \%$, monohydrate) was obtained from Zhengda Tianqing Pharmaceutical Co., Ltd (Jiangsu, China). And all of other chemicals and solvents were commercially available. The structural formula of MI was shown in Fig. 1.

\section{Cell culture}

Human bladder cancer cell lines HTB9 and BIU87 cells were purchased from the American Type Tissue Culture Collection (ATCC), and cultured in RPMI-1640 medium (Solarbio, Beijing, China) containing 10\% FBS (Gibco BRL, Grand Island, NY, USA), 100 unit $/ \mathrm{mL}$ penicillin and $0.1 \mathrm{mg} / \mathrm{mL}$ streptomycin at $37^{\circ} \mathrm{C}$ with $5 \% \mathrm{CO}_{2}$.

\section{Cell transfection}

Cell transfection was performed by using the Lipofectamine RNAi MAX kit (invitrogen) according to the instructions. Of which, miR-26b mimics, miR-26b inhibitor and corresponding negative controls (miR-NC and inhibitor NC) were purchased from Sigma Aldrich.

\section{Luciferase reporter assay}

The fragments of wild type (WT) or mutant type (MUT) 3'UTR of Nox4 was amplified from mouse cDNA and cloned into pRL reporter plasmids. HTB9 and BIU87 cells were co-transfected with luciferase reporter plasmid containing WT or MUT 3'UTR of Nox4 and miR-26b inhibitor or inhibitor NC by using the Lipofectamine RNAi MAX kit. After transfection for $48 \mathrm{~h}$, cells were collected, lysed, and the relative luciferase activity was detected by Dual luciferase reporter system.

\section{MTT assay}

Cell viability was evaluated using the MTT assay as previously described ${ }^{24}$. Briefly, approximately $2 \times 10^{5}$ HTB9 or BIU87 cells were deeded into 96 -well plates and cultured for $24 \mathrm{~h}$. Then cells were treated with different concentrations of Ml such as $0,1.2,5,10$ and $20 \mathrm{mg} / \mathrm{ml}$ for $24 \mathrm{~h}$. Finally, $10 \mu \mathrm{L}$ MTT solution $(5 \mathrm{mg} / \mathrm{mL}$, Sigma) was added to each well and incubated for another $5 \mathrm{~h}$. After medium was aspirated, DMSO (150 $\mu \mathrm{L}$; Sigma) was added to dissolve formazan crystals and the absorbance at $490 \mathrm{~nm}$ was detected using a microplate reader (Biotek, SYNERGY HTX, VT, USA).

\section{Colony formation assay}

Colony formation assay was performed as previously described ${ }^{6}$. In brief, HTB9 and BIU87 cells treated with or without $3.82 \mathrm{mg} / \mathrm{ml}$ or $2.85 \mathrm{Ml}$ were seeded into 6-well plates at a density of 1,000 cells per well and cultured for two weeks. After washing with PBS for twice, cells were fixed with methanol, stained with $0.1 \%$ crystal violet for $25 \mathrm{~min}$, and then the colonies were imaged and counted.

\section{Hoechst 33258 staining assay}


The changes in cellular morphology of HTB9 and BIU87 cells were observed by using Hoechst 33258 staining (Sigma) as previously described ${ }^{25}$. Briefly, HTB9 and BIU87 cells treated with or without $3.82 \mathrm{mg} / \mathrm{ml}$ or $2.85 \mathrm{Ml}$ were seeded into 6-well plates and cultured overnight. Then cells were fixed with $4 \%$ formaldehyde for $15 \mathrm{~min}$, and stained in Hoechst $33258(10 \mathrm{mg} / \mathrm{L})$ for another $1 \mathrm{~h}$. After washing with PBS for twice, cells were subjected to fluorescence microscopy (Olympus, Tokyo, Japan). Meanwhile, the morphological changes including reduction in the volume and nuclear chromatin condensation were observed.

\section{Transwell assay}

The invasion and migration capacities of HTB9 and BIU87 cells was evaluated by transwell assay by using 24-well Transwell ${ }^{\text {TM }}$ plates with or without 8.0- $\mu \mathrm{m}$-pore Matrigel ${ }^{T^{\mathrm{T}}}$-coated membranes previously described ${ }^{26}$. Briefly, approximately $1 \times 10^{5}$ cells in serum-free medium were seeded into the upper chamber, and the lower chamber was filled with medium containing $20 \%$ FBS. The migration assay was performed similarly without coating the membranes with Matrigel ${ }^{\mathrm{TM}}$. After the incubation for $24 \mathrm{~h}$, cells were fixed by $4 \%$ paraformaldehyde and stained with $0.1 \%$ crystal violet. Finally, the numbers of invaded and migrated cells were counted in five randomly selected fields by a microscope.

\section{qRT-PCR}

Total RNA of cultured cells was extracted by using the TRIzol reagent (Invitrogen) according to the manufacturer's instructions. Approximately 1.2 ug RNA was reversely transcribed into cDNA by using the Prime Script RT Master Mix (TaKaRa, Japan) and the qRT-PCR analysis was performed by the SYBR Premix Ex Taq II kit (Takara, Otsu, Japan) based on a Quantstudio ${ }^{\text {TM }}$ DX system (Applied Biosystems, Singapore). The relative expression change of targets was analyzed by $2^{-\Delta \Delta C T}$ method $^{27}$. With GAPDH and $\mathrm{U} 6$ as considered as the internal reference. The primers used in this study as follows:

miRNA-26b: forward: 5'- CTGATGGTTAAGAGAATGT-3',

reverse: 5'-GTCCTTGGACATCCGGGCCG-3';

Nox4: forward: 5'- GATGTTGGGGCTAGGATTGT-3',

reverse: 5'-TCTGTGATCCTCGGAGGTAA-3';

NF-kB: forward: 5'-CACTTATGGACAACTATGAGGTCTCTGG-3',

reverse: 5'-CTGTCTTGTGGACAACGCAGTGGAATTTTAGG-3';

HIF-1a: forward: 5'- AAGAACCTGCCCCAGAAATCACCTGTCTC-3', reverse: 5'-AATGATTTCTGGGGCAGGTTCCCTGTCTC-3';

GAPDH forward primer: 5'-CGAGAGAATCCGCGGACAT-3', 
reverse primer: 5'-TTGTGCAATACAGCGTGGAC-3';

U6: forward: 5'-GACAGATTCGGTCTGTGGCAC-3',

reverse: 5'-GATTACCCGTCGGCCATCGATC-3'.

\section{Western blot}

Total protein of cultured cells was isolated by RIPA Lysis Buffer (Beyotime, Beijing, China) according to the manufacturer's instructions. Approximately equal amounts of protein were separated by $12 \%$ SDSPAGE and transferred into PVDF membranes. After blocking with 5\% non-fat milk, the membranes were incubated with primary antibodies against Nox4 (Ab9574, 1:1000, abcam), NF-KB p65 (Ab3771,1:1000, abcam), HIF-1a (Ab9574, 1:1000, abcam) and $\beta$-actin (Ab8227, 1:1000, abcam, Cambridge, MA) at $4^{\circ} \mathrm{C}$ overnight, followed by incubation with appropriate HRP-conjugated secondary antibodies at room temperature for another $1 \mathrm{~h}$. Positive signals were detected by using an ECL kit (Millipore, Germany), and bands were visualized under a Bio-Rad imaging system.

\section{Flow cytometer assay}

Cell apoptosis was evaluated by using the Annexin V-FITC/PI apoptosis detection kit (Keygen Biotech, Nanjing, China) according to the manufacturer's instructions. Briefly, cells treated with or without $3.82 \mathrm{mg} / \mathrm{ml}$ or $2.85 \mathrm{Ml}$ were seeded into 6 -well plates at a density of approximately $1 \times 10^{5} \mathrm{cell} / \mathrm{s} / \mathrm{ml}$. Then cells were collected, harvested, washed and re-suspended in binding buffer. After stained with Annexin VFITC at room temperature for 20 min in dark, PI was added into each well and incubated for another 10 min. The apoptosis rate of cells was analyzed by a FACSCalibur flow cytometer within $1 \mathrm{~h}$ after supravital staining.

\section{Animal model}

The female BALB/c nude mice (6-week-old, weighing approximately $20.0 \pm 2.0 \mathrm{~g}$ ) were purchased from The First Affiliated Hospital of Zhengzhou University. Mice were kept at room temperature with 12/12-h light-dark cycle, and all animal handling procedures were performed in strict according to the PR China legislation of the use and care of laboratory animals. This study was approved by The First Affiliated Hospital of Zhengzhou University HTB9 tumor-bearing mice model was established as previously described with minor modulation28. In brief, HTB9 cells were intraperitoneally injected into the abdominal cavity of BALB/c nude mice, and the ascites were removed from mice and diluted to $1 \times 10^{7} \mathrm{cell} / \mathrm{s} / \mathrm{ml}$ with physiological saline. Then $0.2 \mathrm{~mL}$ of the cells were subcutaneously injected into the right armpit of mice to establish the solid tumor model. To determine the effect of $\mathrm{M} /$ in vivo, mice were randomly divided into two groups $(n=10)$, model group and Ml group. Ml groups were intragastrically given the certain dose $(0.1 \mathrm{~mL} / 10 \mathrm{~g}$ body weight.) of Ml once daily for 5 weeks, and model groups were given the same volume of normal saline, simultaneously. Tumor volume was calculated by using the following formula: (length $x$ 
width $\left.{ }^{2}\right) / 2$. When experiments were finished, mice were sacrificed, and the excised tumors were removed, weighted, and photographed.

\section{Statistical analysis}

All data were presented as the mean \pm SE method which was derived from at three independent experiments. The difference between groups was determined by Two-tailed Student's t-test or one-way ANOVA. Statistical analysis was performed by the SPSS software $v 18.0$ with $p<0.05$ as the significant threshold.

\section{Results}

\section{Ml inhibited the growth and colony formation of bladder cancer cells in vitro}

To explore the effect of MI in bladder cancer, bladder cancer cell lines HTB9 and BIU87 cells were treated with different concentrations of Ml such as $0,1.2,5,10$ and $20 \mathrm{mg} / \mathrm{ml}$ for $24 \mathrm{~h}$. MTT assay indicated that MI obviously decreased the cell viability in a dose dependent manner and exhibited the significant decrease at 5, 10 and $20 \mathrm{mg} / \mathrm{ml}$ both in HTB9 and BIU87 cells $(p<0.01)$ (Fig. 2A). Further, The IC50 value calculated by SPSS software was $3.82 \mathrm{mg} / \mathrm{mL}$ in HTB9 cells and $2.85 \mathrm{mg} / \mathrm{mL}$ in BIU87 cells, which was selected for the subsequent experiments. Then the colony formation assay was performed and the results showed that MI significantly inhibited the colony formation both in HTB9 $(p<0.01)$ and BIU87 cells $(p<0.01)$. These results suggested that Ml could efficiently inhibit the growth of bladder cancer cells, and had high selectivity to tumor cells in vitro.

\section{Ml promoted the apoptosis of bladder cancer cells in vitro}

Further, the apoptosis of bladder cancer cell lines HTB9 and BIU87 cells was observed by Hoechst 33258 staining assay (Fig. 3). From the morphological changes of cell apoptosis, the condensation of chromosome and nuclear fragmentation were obviously observed both in HTB9 (Fig. 3A) and BIU87 cells (Fig. 3B) when cells exposed to $\mathrm{Ml}$, and apoptotic cells were approximately between $50-80 \%$. These results suggested that $\mathrm{Ml}$ could significantly promote the condensation of chromosome and nuclear fragmentation in bladder cancer cells in vitro.

\section{Ml inhibited the invasion, migration and induced apoptosis of bladder cancer cells in vitro}

Next, transwell assay was performed to explore the effect of MI on cell invasion and migration, and the results indicated that MI significantly inhibited the migration capacity of both HTB9 $(p<0.01)$ and BIU87 cells $(p<0.01)$ (Fig. 4A). Similarly, Ml also markedly suppressed the invasion capacity of both HTB9 ( $p<$ $0.01)$ and BIU87 cells $(p<0.01)$ (Fig. 4B). Meanwhile, the effect of MI in the apoptosis rate of HTB9 and BIU87 cells was evaluated by flow cytometry, and the results revealed that MI significantly promote the apoptosis of both HTB9 $(p<0.01)$ and BIU87 cells $(p<0.01)$ (Fig. 4C). These results suggested that MI could efficiently inhibit the invasion, migration and induce apoptosis of bladder cancer cells in vitro. 


\section{MI suppressed the activation of Nox4/NF-KB/HIF-1a signaling pathways in vitro}

We also explore the effect of MI on the Nox4/NF-KB/HIF-1a signaling pathway in vitro. HTB9 were treated with $3.82 \mathrm{mg} / \mathrm{mL}$ and BIU87 cells were treated with $2.85 \mathrm{mg} / \mathrm{mL}$, and the expression of Nox4, NF-KB and HIF-1a was evaluated by qRT-PCR and western blot. The results showed that MI significantly decreased the mRNA level of Nox4 ( $p<0.01)$, NF-KB $(p<0.01)$ and HIF-1 $a(p<0.01)$ both in HTB9 and BIU87 cells (Fig. 5A). In addition, in HTB9 cells, MI obviously decreased the protein expression of Nox4 $(p<0.01)$, NFKB $(p<0.01)$ and HIF-1a $(p<0.01)$ (Fig. 5B); Similarly, MI also significantly decreased the protein level of Nox4 ( $p<0.01)$, NF-KB $(p<0.01)$ and HIF-1a $(p<0.01)$ in BIU87 cells (Fig. 5C). These results indicated that $\mathrm{MI}$ could inhibit the activation of Nox4/NF-KB/HIF-1a signaling pathway in bladder cancer cells in vitro.

\section{Nox4 Was A Direct Target Of Mir-26b}

Interestingly, we found that MI significantly increased the expression of miR-26b both in HTB9 $(p<0.01)$ and BIU87 cells ( $\mathrm{p}<0.01$ ) (Fig. 6A). To explore the specific mechanisms of miR-26b in response to MI, Targetscan was used to predict the potential targets of miR-26b, and the results showed that there was a putative binding site between miR-26b and Nox4 (Fig. 6B), suggesting that Nox4 might be a target of miR$26 \mathrm{~b}$. Then luciferase reporter assay was performed and revealed that miR-26b mimics significantly decreased the relative luciferase of Nox4 WT vector compared with miR-NC control $(p<0.01)$, while exhibited no obvious change in Nox4 MUT vector (Fig. 6C). Meanwhile, miR-26b inhibitor significantly increased the relative luciferase of Nox4 WT vector compared with inhibitor NC control $(p<0.01)$, while showed no obvious change in Nox4 MUT vector (Fig. 6D). In addition, miR-26b mimics markedly decreased the protein expression of Nox4 compared with miR-NC control $(p<0.01)$, while miR-26 inhibitor significantly increased the protein level of Nox4 compared with inhibitor NC control (Fig. 6E). These results indicated that Nox4 was a target of miR-26b, and the effect of $\mathrm{Ml}$ in bladder cancer was mediated by miR-26b/Nox4 axis.

\section{Ml efficiently repressed the progression of bladder cancer in vivo}

Finally, the xenograft rat model was established to determine the anticancer effect of MI in bladder cancer. The representative images of xenograft tumors from model group and MI group was shown in Fig. 7A. As expected, the tumor weight was significantly decreased in MI group compared with model group ( $p$ < 0.01) (Fig. 7B). Meanwhile, the tumor volume was obviously decreased in a time dependent manner in MI group compared with model group ( $\mathrm{p}<0.01$ ) (Fig. 7C). In addition, Ki-67 staining assay showed that the numbers of positive cells in $\mathrm{Ml}$ group were markedly decreased compared with model group (Fig. 7D), suggesting that MI efficiently inhibited the proliferation of bladder cancer cells. Moreover, compared with model group, the protein level of Nox4 $(p<0.01)$, NF-KB $(p<0.01)$ and HIF-1a $(p<0.01)$ was significantly decreased compared with model group (Fig. 7E). These results demonstrated that MI could efficiently repress the progression of bladder cancer in vivo. 


\section{Discussion}

Due to its higher recurrence rate, bladder cancer brings to patients physical agony and high therapy costs to the patients' family and society 29,30 . Hence, a lot of attentions have focused on the diagnosis or treatment in bladder cancer ${ }^{31}$. In the last decades, a series of natural or unnatural components have been identified and demonstrated to show a certain anti-tumor activity for bladder cancer. For example, sulforaphane, a natural agent that was abundant in cruciferous vegetables, has been demonstrated to suppress the proliferation of non-muscle invasive bladder cancer cells via blocking HIF-1a-mediated glycolysis in hypoxia ${ }^{32}$. Inoue et al. reported a 5-Aminolevulinic acid-mediated photodynamic therapy for bladder cancer, and some favorable outcomes have been achieved clinically ${ }^{33}$. It was also reported that curcumin, a yellow substance belonging to the polyphenols superfamily, has been revealed that can attenuate the progression of bladder cancer partially through suppressing the Sp- 1 activity ${ }^{34}$. In addition, amygdalin, a natural compound, has been demonstrated to efficiently inhibit the growth of bladder cancer cells in vitro through diminishing cyclin A and cdk2 ${ }^{35}$. Despite many anti-tumor agents for bladder cancer have been identified, the identification of specific and efficient anti-bladder cancer agents is still urgent. In this study, we explore the effect of a hepatoprotective agent MI in bladder cancer, and revealed that MI could significantly inhibit the growth, invasion, migration and induce apoptosis of bladder cancer cell lines including HTB9 and BIU87 cells in vitro, suggesting a protective role of MI in bladder cancer development.

MiRNAs have been identified to play essential roles in tumorigenesis and metastasis through negatively regulating gene expression by directly targeting the 3'-UTR in bladder cancer. MiR-217 has been reported to inhibit the proliferation and migration of bladder cancer cells through targeting KMT2 ${ }^{36}$. MiR-556-3p can exacerbate the capacity of proliferation, migration and invasion of human bladder cancer cells via negatively regulating the expression of $\mathrm{DAB} 2 \mathrm{IP} \mathrm{P}^{37}$. Xie et al. have revealed that downregulation of miR532-5p can significantly promote the proliferation and invasion of bladder cancer cells by activating the HMGB3/Wnt/ $\beta$-catenin signaling pathway ${ }^{38}$. MiR-124-3p has also been found that can suppress cell migration and invasion of bladder cancer cells through targeting ITGA3 ${ }^{39}$. MiR-129-5p suppresses gemcitabine resistance and promotes the apoptosis of bladder cancer cells via targeting Wnt5a $\mathrm{a}^{40}$. In addition, there are many other miRNAs including miR-223 ${ }^{41}$, miR- $1265^{42}$, miR-125a-5p ${ }^{43}$, miR- $155^{44}$, and so on which were significantly involved in the progression of bladder cancer. In the present study, we found that MI could significantly increase the expression of miR-26b in bladder cancer cell lines such as HTB9 and BIU87 cells, suggesting that the protective effect of MI in bladder cancer was mediated by miR$26 \mathrm{~b}$.

To explore the specific mechanisms of miR-26b induced by MI in bladder cancer, targetscan was applied to predict the potential targets of miR-26b and found that Nox4 might a direct target of miR-26b. Meitzler et al. found that the expression of Nox4 was significantly upregulated in the carcinoma of bladder cancer patients compared with normal controls ${ }^{45}$. Recently, NAD(P)H oxidase 4 (Nox4) have been revealed to play important roles in the invasion of bladder cancer cells ${ }^{46}$. One previous study reported that 
knockdown of NOx4 exhibits a significant inhibitory effect on survival, and induces apoptosis of bladder cancer cells ${ }^{47}$. These reports all confirmed a tumorigenic role of Nox4 in bladder cancer. To determine the interaction between miR-26b and Nox4, the luciferase reporter assay was performed and showed that miR-26b mimics significantly decreased the relative luciferase of Nox4 WT vector, while miR-26b inhibitor significantly increased the relative luciferase of Nox4 WT vector. Meanwhile, downregulation of miR-26b significantly increased the expression of Nox4, and upregulation of miR-26b reversely decreased Nox4 expression. In addition, MI could obviously decrease the expression of Nox4 both in vitro and in vivo. These results demonstrated that Nox4 was a direct target of miR-26, and the effect of Ml in bladder cancer was mediated by miR-26b/Nox4 axis.

Cell proliferation is one of the main features of solid tumor progression, and the rapid tumor cell growth usually results in hypoxia because of the low oxygen environment ${ }^{32}$. A previous study indicated that one of the key factors regulating the response to hypoxia is the heterodimer hypoxia-inducible factor- $1 \mathrm{a}$ (HIF$1 a)^{48}$. A series of previous studies have demonstrated that HIF-1a can exacerbate the progression of bladder cancer including promoting EMT process ${ }^{49}$, growth ${ }^{50}$, and conferring the chemo-resistance to cisplatin of bladder cancer cells ${ }^{51}$. It has been reported that NF-KB inhibits the apoptosis and promotes the proliferation of bladder cancer cells through upregulating the expression of survivin both in vitro and in vivo ${ }^{52}$. Here, our results showed that MI could markedly decreased the expression of NF-KB and HIF-1a both in in vitro and in vivo. Moreover, the experiments in vivo demonstrated that Ml could efficiently inhibit the development of bladder cancer, suggesting that MI might be a potential anti-tumor agent for bladder cancer.

However, there was few limit in this study: although our results suggested that $\mathrm{MI}$ inhibited the progression of bladder cancer through suppressing Nox4/NF-KB/HIF-1a signaling, the Nox4/NF-KB/HIF1a signaling-related inhibitor (upregulation of Nox4, NF-KB or HIF-1a) whether reversed the protective effect of $\mathrm{Ml}$ in bladder cancer needed to be determined in the further.

\section{Conclusion}

In summary, MI could efficiently inhibit the progression of bladder cancer both in in vitro and in vivo through inhibiting Nox4/NF-KB/HIF-1a signaling pathway by directly upregulating the expression of miR$26 \mathrm{~b}$, suggesting that $\mathrm{MI}$ might be a potential and safe anticancer bioactive agent for bladder cancer.

\section{Abbreviations}

Magnesium Isoglycyrrhizinate Ml; wild type:WT; P-glycoprotein :Pgp; NAD(P)H oxidase 4: Nox4; non-small cell lung cancer:NSCLC.

\section{Declarations}

\section{Ethics approval and consent to participate}


The present study was approved by The First Affiliated Hospital of Zhengzhou University. The research has been carried out in accordance with the World Medical Association Declaration of Helsinki. All patients and healthy volunteers provided written informed consent prior to their inclusion within the study.

\section{Consent for publication}

All authors have read and approved the final manuscript.

\section{Availability of data and materials}

The analyzed data sets generated during the study are available from the corresponding author on reasonable request.

\section{Competing interests}

There was no any conflict of interest.

\section{Funding:}

Not applicable

\section{Authors contribution}

ZHY and GCG concept, study design, experiments, manuscript preparation. GFS, QL BPQ and LHW experiments, data analysis, manuscript preparation. All authors have read and approved the manuscript.

\section{Acknowledgement}

Not applicable

\section{References}

1. Martinez Rodriguez RH, Buisan Rueda O, Ibarz L. Bladder cancer: Present and future. Medicina clinica 2017; 149:449-55.

2. Antoni S, Ferlay J, Soerjomataram I, Znaor A, Jemal A, Bray F. Bladder Cancer Incidence and Mortality: A Global Overview and Recent Trends. European urology 2017; 71:96-108.

3. Malats N, Real FX. Epidemiology of bladder cancer. Hematology/oncology clinics of North America $2015 ; 29: 177-89$, vii.

4. Alfred Witjes J, Lebret T, Compérat EM, Cowan NC, De Santis M, Bruins HM, Hernández V, Espinós EL, Dunn J, Rouanne M, et al. Updated 2016 EAU Guidelines on Muscle-invasive and Metastatic Bladder Cancer. European urology 2017; 71:462-75.

5. Siegel RL, Miller KD, Jemal A. Cancer statistics, 2015. CA: a cancer journal for clinicians 2015; 65:529. 
6. Han J, Wang JZ, Yang X, Yu H, Zhou R, Lu HC, Yuan WB, Lu JC, Zhou ZJ, Lu Q, et al. METTL3 promote tumor proliferation of bladder cancer by accelerating pri-miR221/222 maturation in m6Adependent manner. 2019; 18:110.

7. Del Ben M, Polimeni L, Baratta F, Pastori D, Angelico F. The role of nutraceuticals for the treatment of non-alcoholic fatty liver disease. British journal of clinical pharmacology 2017; 83:88-95.

8. Huang X, Qin J, Lu S. Magnesium isoglycyrrhizinate protects hepatic L02 cells from ischemia/reperfusion induced injury. International journal of clinical and experimental pathology 2014; 7:4755-64.

9. Zheng J, Wu G, Hu GX, Peng YZ, Xiong XJ. Protective effects against and potential mechanisms underlying the effect of magnesium isoglycyrrhizinate in hypoxia-reoxygenation injury in rat liver cells. Genetics and molecular research : GMR 2015; 14:15453-61.

10. Yan Y, Mo Y, Zhang D. [Magnesium isoglycyrrhizinate prevention of chemotherapy-induced liver damage during initial treatment of patients with gastrointestinal tumors]. Zhonghua gan zang bing za zhi = Zhonghua ganzangbing zazhi = Chinese journal of hepatology 2015; 23:204-8.

11. Chen KJ, Chen WY, Chen X, Jia YM, Peng GQ, Chen L. Increased elimination of paclitaxel by magnesium isoglycyrrhizinate in epithelial ovarian cancer patients treated with paclitaxel plus cisplatin: a pilot clinical study. European journal of drug metabolism and pharmacokinetics 2014; 39:25-31.

12. Zhao Z, Tang Z, Zhang W, Liu J, Li B. Magnesium isoglycyrrhizinate protects against renal-ischemia-reperfusion injury in a rat model via anti-inflammation, anti-oxidation and anti-apoptosis. Molecular medicine reports 2017; 16:3627-33.

13. Ma D, Zhang J, Zhang Y, Zhang X, Han X, Song T, Zhang Y, Chu L. Inhibition of myocardial hypertrophy by magnesium isoglycyrrhizinate through the TLR4/NF-KB signaling pathway in mice. International immunopharmacology 2018; 55:237-44.

14. Li TS, Chen L, Wang SC, Yang YZ, Xu HJ, Gu HM, Zhao XJ, Dong P, Pan Y, Shang ZQ, et al. Magnesium isoglycyrrhizinate ameliorates fructose-induced podocyte apoptosis through downregulation of miR-193a to increase WT1. Biochemical pharmacology 2019; 166:139-52.

15. Lu TX, Rothenberg ME. MicroRNA. The Journal of allergy and clinical immunology 2018; 141:1202-7.

16. Wang B, Lu FY, Shi RH, Feng YD, Zhao XD, Lu ZP, Xiao L, Zhou GQ, Qiu JM, Cheng CE. MiR-26b regulates 5-FU-resistance in human colorectal cancer via down-regulation of Pgp. American journal of cancer research 2018; 8:2518-27.

17. Li J, Liang Y, Lv H, Meng H, Xiong G, Guan X, Chen X, Bai Y, Wang K. miR-26a and miR-26b inhibit esophageal squamous cancer cell proliferation through suppression of c-MYC pathway. Gene 2017; 625:1-9.

18. Gao Y, Yang F. [MiR-26b regulates invasion and migration of lung cancer cells through targeting hENT1 depending on RhoA/ROCK-1 pathway]. Zhong nan da xue xue bao Yi xue ban = Journal of Central South University Medical sciences 2017; 42:755-61. 
19. Tang CT, Gao YJ, Ge ZZ. NOX4, a new genetic target for anti-cancer therapy in digestive system cancer. Journal of digestive diseases 2018; 19:578-85.

20. Zeng C, Wu Q, Wang J, Yao B, Ma L, Yang Z, Li J, Liu B. NOX4 supports glycolysis and promotes glutamine metabolism in non-small cell lung cancer cells. Free radical biology \& medicine 2016; 101:236-48.

21. Tang CT, Lin XL, Wu S, Liang Q, Yang L, Gao YJ, Ge ZZ. NOX4-driven ROS formation regulates proliferation and apoptosis of gastric cancer cells through the GLI1 pathway. Cellular signalling 2018; 46:52-63.

22. Du S, Miao J, Lu X, Shi L, Sun J, Xu E, Wang X, Zhao M, Chen H, Wang F, et al. NADPH oxidase 4 is correlated with gastric cancer progression and predicts a poor prognosis. American journal of translational research 2019; 11:3518-30.

23. Shimada K, Fujii T, Anai S, Fujimoto K, Konishi N. ROS generation via NOX4 and its utility in the cytological diagnosis of urothelial carcinoma of the urinary bladder. BMC urology 2011; 11:22.

24. Wang LS, Chen SJ, Zhang JF, Liu MN, Zheng JH, Yao XD. Anti-proliferative potential of Glucosamine in renal cancer cells via inducing cell cycle arrest at G0/G1 phase. BMC urology 2017; 17:38.

25. Wang $Y$, Xiang W, Wang $M$, Huang T, Xiao X, Wang L, Tao D, Dong L, Zeng F, Jiang G. Methyl jasmonate sensitizes human bladder cancer cells to gambogic acid-induced apoptosis through down-regulation of EZH2 expression by miR-101. British journal of pharmacology 2014; 171:618-35.

26. Lu Q, Liu T, Feng H, Yang R, Zhao X, Chen W, Jiang B, Qin H, Guo X, Liu M, et al. Circular RNA circSLC8A1 acts as a sponge of miR-130b/miR-494 in suppressing bladder cancer progression via regulating PTEN. 2019; 18:111.

27. Livak KJ, Schmittgen TD. Analysis of relative gene expression data using real-time quantitative PCR and the 2(-Delta Delta C(T)) Method. Methods (San Diego, Calif) 2001; 25:402-8.

28. Cao W, Zhao Y, Wang L, Huang X. Circ0001429 regulates progression of bladder cancer through binding miR-205-5p and promoting VEGFA expression. Cancer biomarkers : section A of Disease markers 2019; 25:101-13.

29. Farling KB. Bladder cancer: Risk factors, diagnosis, and management. The Nurse practitioner 2017; 42:26-33.

30. Smith AB, Jaeger B, Pinheiro LC, Edwards LJ, Tan HJ, Nielsen ME, Reeve BB. Impact of bladder cancer on health-related quality of life. BJU international 2018; 121:549-57.

31. Smith AB. Recent developments in the management of bladder cancer: Introduction. Urologic oncology 2018; 36:95-6.

32. Xia Y, Kang TW, Jung YD, Zhang C, Lian S. Sulforaphane Inhibits Nonmuscle Invasive Bladder Cancer Cells Proliferation through Suppression of HIF-1a-Mediated Glycolysis in Hypoxia. 2019; 67:7844-54.

33. Inoue K. 5-Aminolevulinic acid-mediated photodynamic therapy for bladder cancer. International journal of urology : official journal of the Japanese Urological Association 2017; 24:97-101. 
34. Vallianou NG, Evangelopoulos A, Schizas N, Kazazis C. Potential anticancer properties and mechanisms of action of curcumin. Anticancer research 2015; 35:645-51.

35. Makarević J, Rutz J, Juengel E, Kaulfuss S, Reiter M, Tsaur I, Bartsch G, Haferkamp A, Blaheta RA. Amygdalin blocks bladder cancer cell growth in vitro by diminishing cyclin A and cdk2. PloS one 2014; 9:e105590.

36. Hou G, Xu W, Jin Y, Wu J, Pan Y, Zhou F. MiRNA-217 accelerates the proliferation and migration of bladder cancer via inhibiting KMT2D. Biochemical and biophysical research communications 2019; 519:747-53.

37. Feng C, Sun P, Hu J, Feng H, Li M, Liu G, Pan Y, Feng Y, Xu Y, Feng K, et al. miRNA-556-3p promotes human bladder cancer proliferation, migration and invasion by negatively regulating DAB2IP expression. International journal of oncology 2017; 50:2101-12.

38. Xie X, Pan J, Han X, Chen W. Downregulation of microRNA-532-5p promotes the proliferation and invasion of bladder cancer cells through promotion of HMGB3/Wnt/ $\beta$-catenin signaling. Chemicobiological interactions 2019; 300:73-81.

39. Wang JR, Liu B, Zhou L, Huang YX. MicroRNA-124-3p suppresses cell migration and invasion by targeting ITGA3 signaling in bladder cancer. Cancer biomarkers : section A of Disease markers 2019; 24:159-72.

40. Cao J, Wang Q, Wu G, Li S, Wang Q. miR-129-5p inhibits gemcitabine resistance and promotes cell apoptosis of bladder cancer cells by targeting Wnt5a. International urology and nephrology 2018; 50:1811-9.

41. Sugita S, Yoshino H, Yonemori M, Miyamoto K, Matsushita R, Sakaguchi T, Itesako T, Tatarano S, Nakagawa M, Enokida H. Tumor-suppressive microRNA-223 targets WDR62 directly in bladder cancer. International journal of oncology 2019; 54:2222-36.

42. Yan D, Dong W, He Q, Yang M, Huang L, Kong J, Qin H, Lin T, Huang J. Circular RNA circPICALM sponges miR-1265 to inhibit bladder cancer metastasis and influence FAK phosphorylation. EBioMedicine 2019; 48:316-31.

43. Zhang Y, Zhang D, Lv J, Wang S, Zhang Q. MiR-125a-5p suppresses bladder cancer progression through targeting FUT4. Biomedicine \& pharmacotherapy = Biomedecine \& pharmacotherapie 2018; 108:1039-47.

44. Lu JJ, Yang WM, Li F, Zhu W, Chen Z. Tunneling Nanotubes Mediated microRNA-155 Intercellular Transportation Promotes Bladder Cancer Cells' Invasive and Proliferative Capacity. International journal of nanomedicine 2019; 14:9731-43.

45. Meitzler JL, Makhlouf HR, Antony S, Wu Y, Butcher D, Jiang G, Juhasz A, Lu J, Dahan I, Jansen-Dürr P, et al. Decoding NADPH oxidase 4 expression in human tumors. Redox biology 2017; 13:182-95.

46. Kim EY, Seo JM, Kim C, Lee JE, Lee KM, Kim JH. BLT2 promotes the invasion and metastasis of aggressive bladder cancer cells through a reactive oxygen species-linked pathway. Free radical biology \& medicine 2010; 49:1072-81. 
47. Seo JM, Cho KJ, Kim EY, Choi MH, Chung BC, Kim JH. Up-regulation of BLT2 is critical for the survival of bladder cancer cells. Experimental \& molecular medicine 2011; 43:129-37.

48. Adams JM, Difazio LT, Rolandelli RH, Luján JJ, Haskó G, Csóka B, Selmeczy Z, Németh ZH. HIF-1: a key mediator in hypoxia. Acta physiologica Hungarica 2009; 96:19-28.

49. Zhu J, Huang Z, Zhang M, Wang W, Liang H, Zeng J, Wu K, Wang X, Hsieh JT, Guo P, et al. HIF-1a promotes ZEB1 expression and EMT in a human bladder cancer lung metastasis animal model. Oncology letters 2018; 15:3482-9.

50. Fus $Ł P$, Pihowicz P, Koperski $Ł$, Marczewska JM, Górnicka B. HIF-1a expression is inversely associated with tumor stage, grade and microvessel density in urothelial bladder carcinoma. Polish journal of pathology : official journal of the Polish Society of Pathologists 2018; 69:395-404.

51. Sun Y, Guan Z, Liang L, Cheng Y, Zhou J, Li J, Xu Y. HIF-1a/MDR1 pathway confers chemoresistance to cisplatin in bladder cancer. Oncology reports 2016; 35:1549-56.

52. Cui X, Shen D, Kong C, Zhang Z, Zeng Y, Lin X, Liu X. NF-kB suppresses apoptosis and promotes bladder cancer cell proliferation by upregulating survivin expression in vitro and in vivo. Scientific reports $2017 ; 7: 40723$.

\section{Figures}

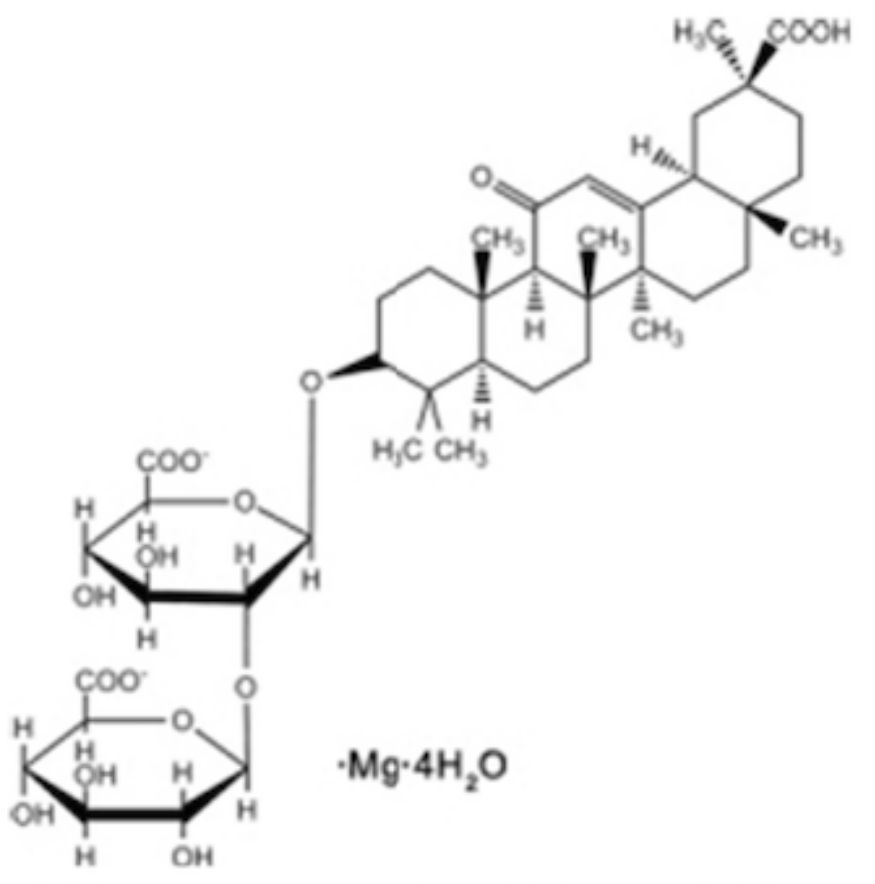

Figure 1 
The structural formula of MI.

A

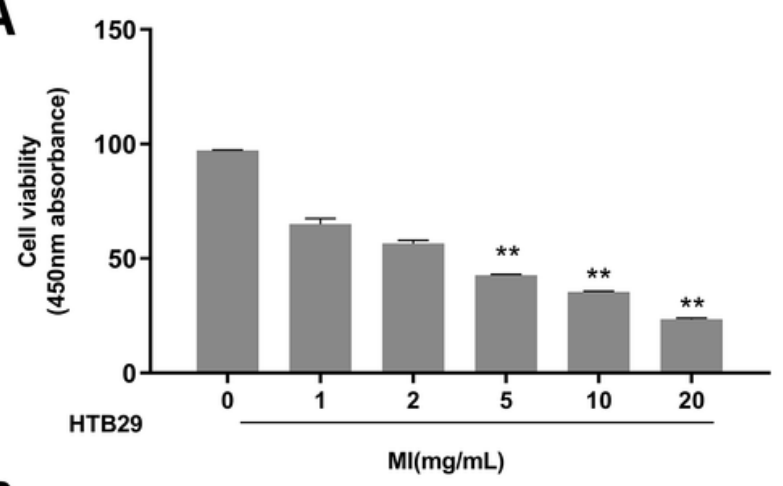

B

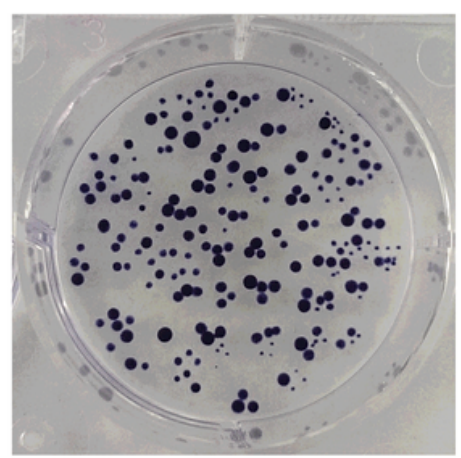

3.82
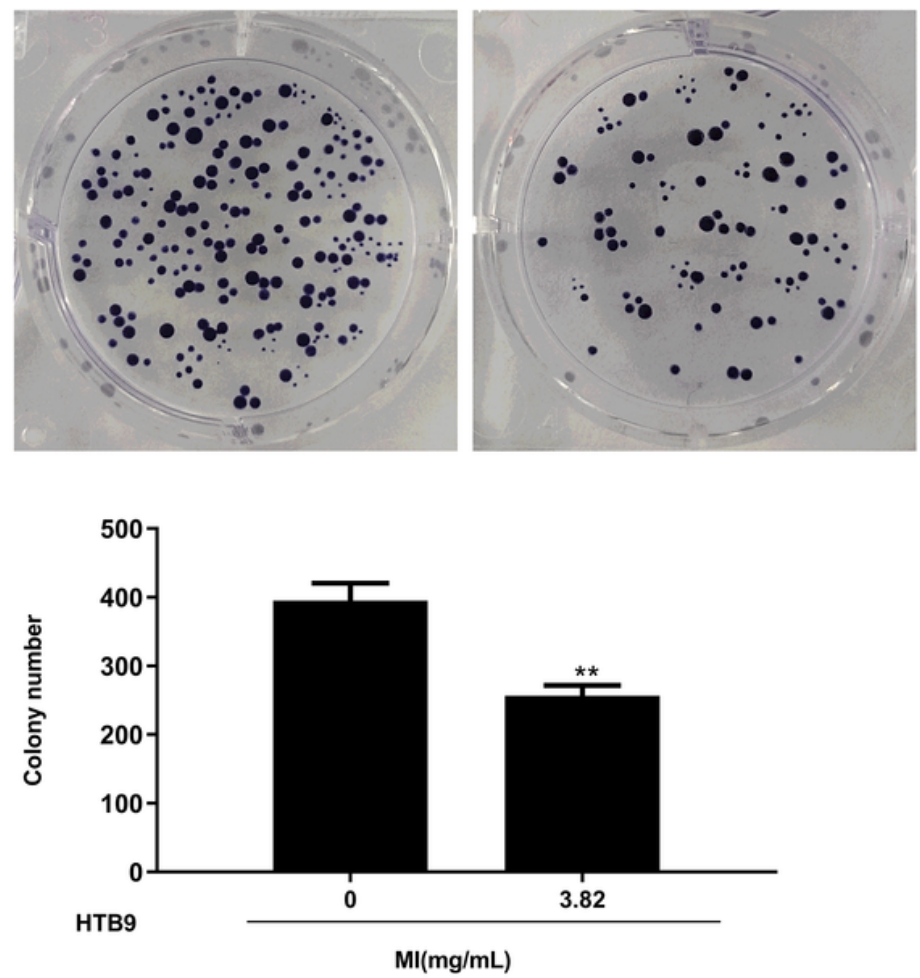

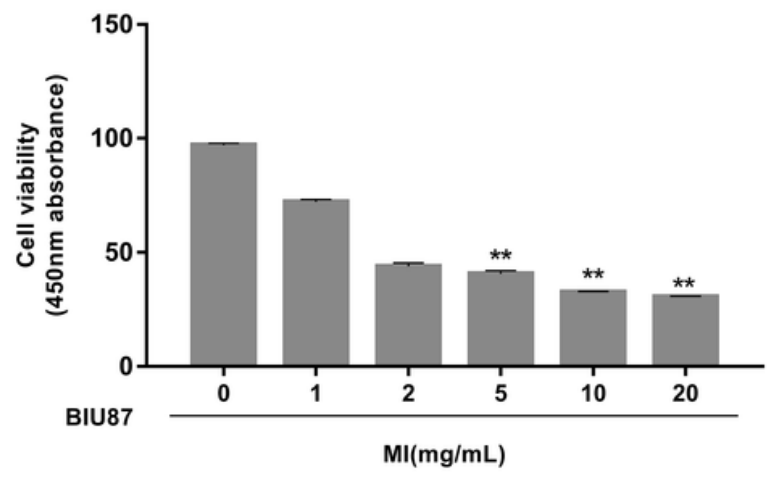

0

2.85
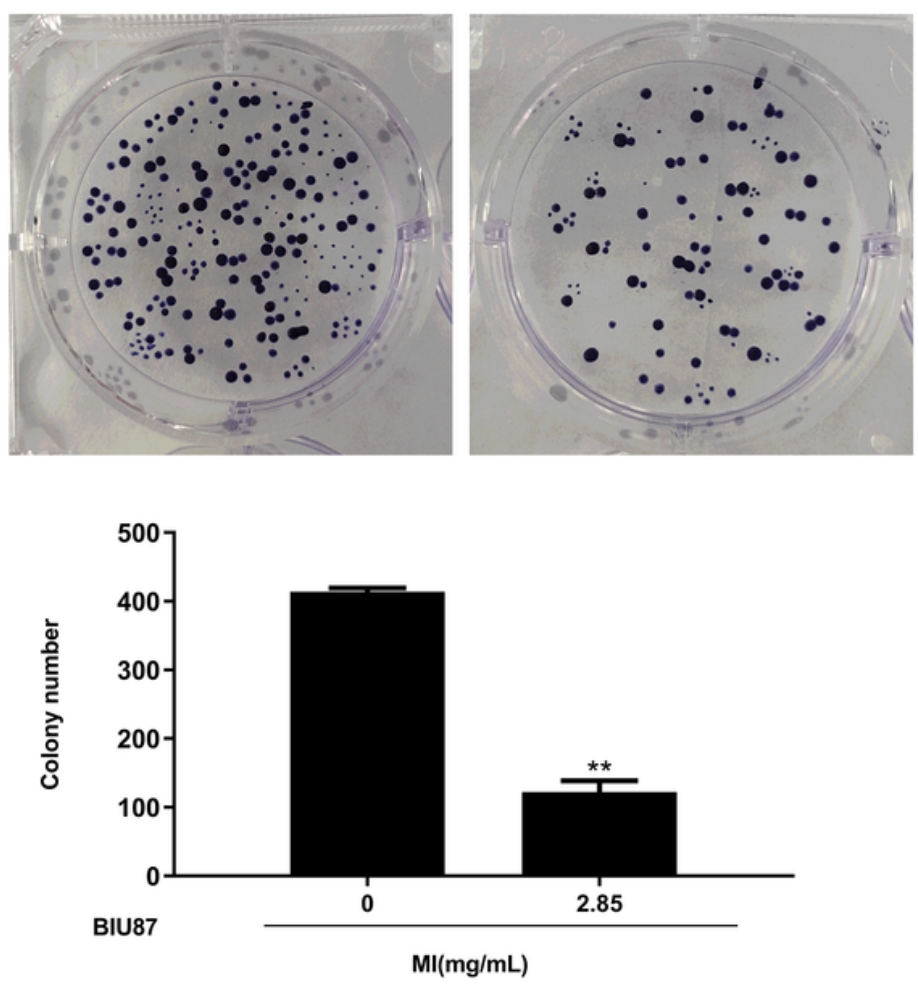

Figure 2

MI inhibited the growth and colony formation of bladder cancer cells in vitro. (A) HTB9 and BIU87 cells were treated with $0,1.2,5,10$ and $20 \mathrm{mg} / \mathrm{ml} \mathrm{Ml}$ for $24 \mathrm{~h}$, and cell viability was evaluated by MTT assay. (B) HTBP cells were treated with $3.82 \mathrm{mg} / \mathrm{mL} \mathrm{MI}$ and BIU87 cells were treated with $2.85 \mathrm{mg} / \mathrm{mL} \mathrm{Ml}$, and the cell growth was evaluated by colony formation assay. $N=6$, $* \star P<0.01$. 
A

HTB9

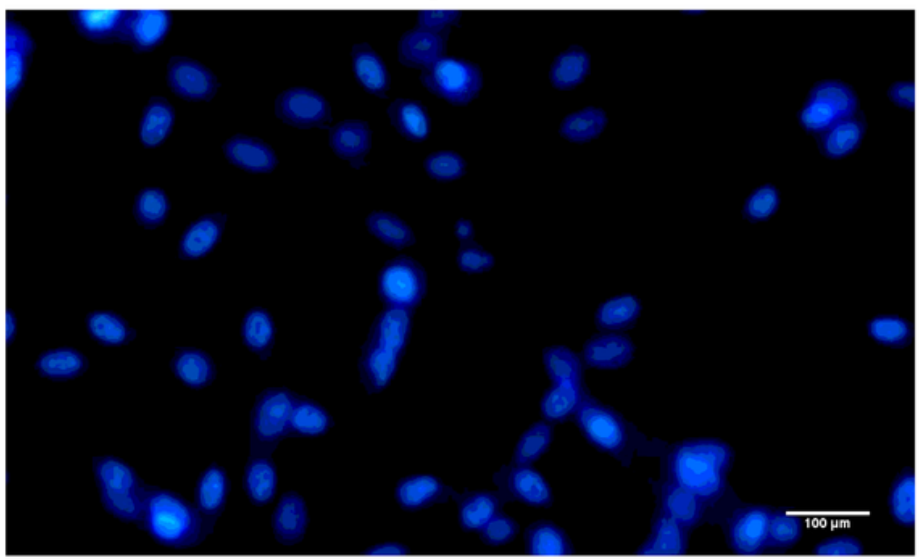

B

BIU87

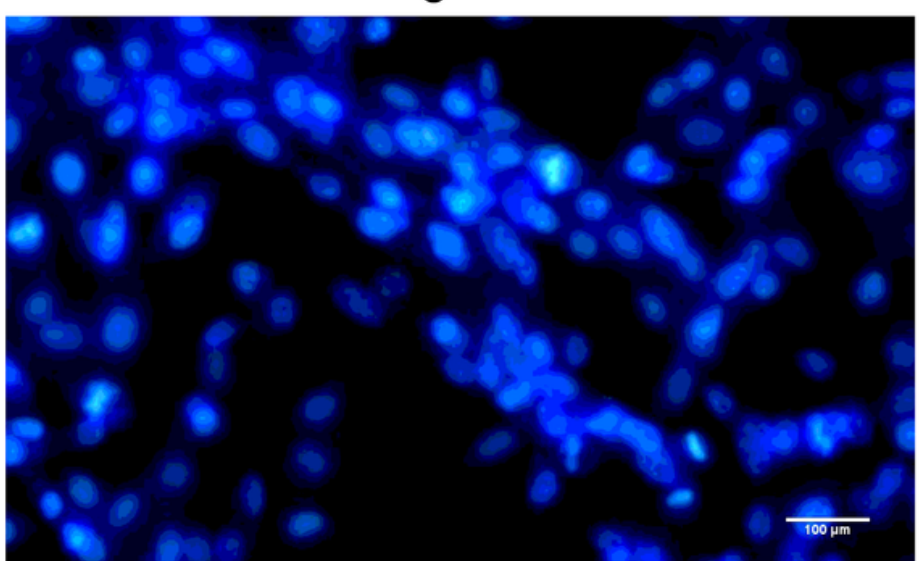

3.82

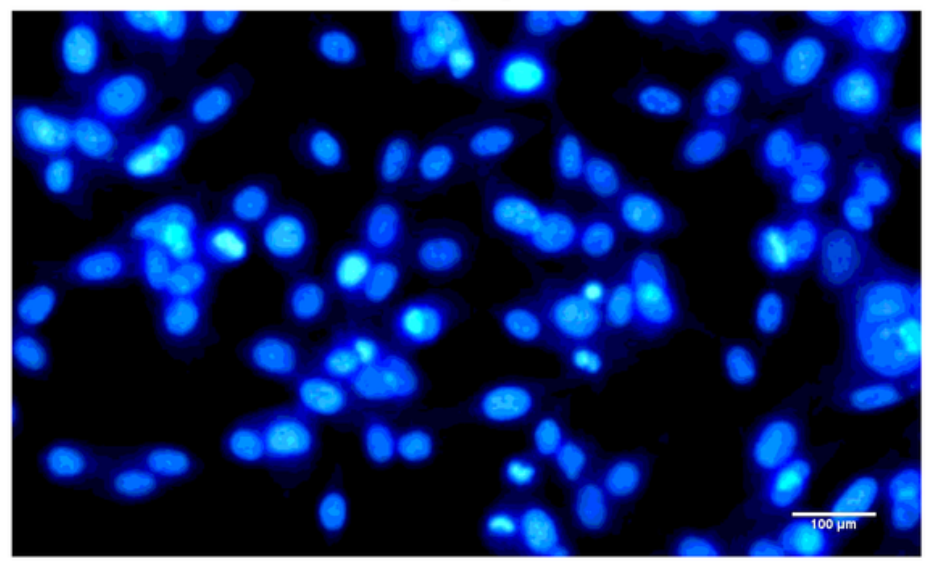

\subsection{2}

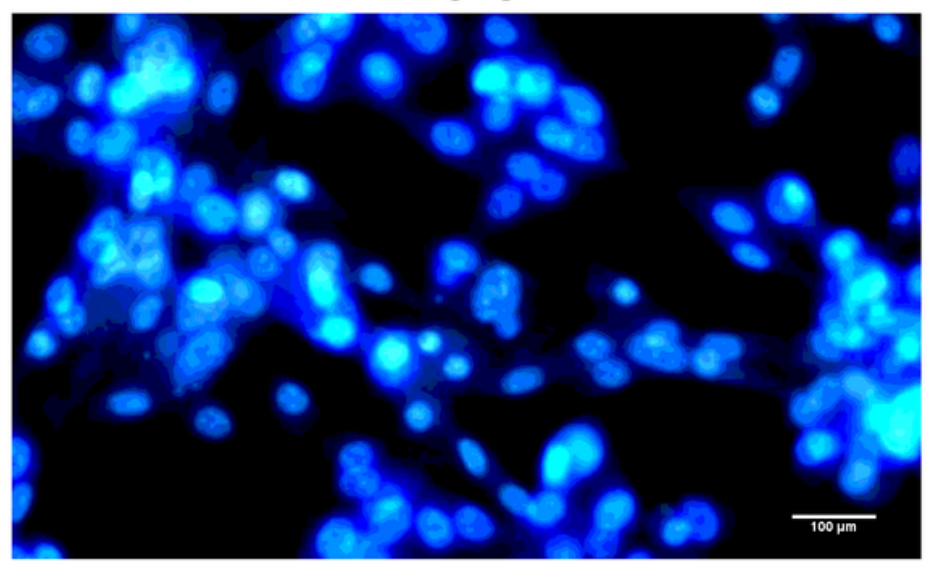

Figure 3

Effect of MI on the morphological changes in bladder cancer cells was observed by Hoechst 33258 staining assay. (A) HTB9 cells. (B) BIU87 cells. $N=6$, hoechst staining $\times 400$. 


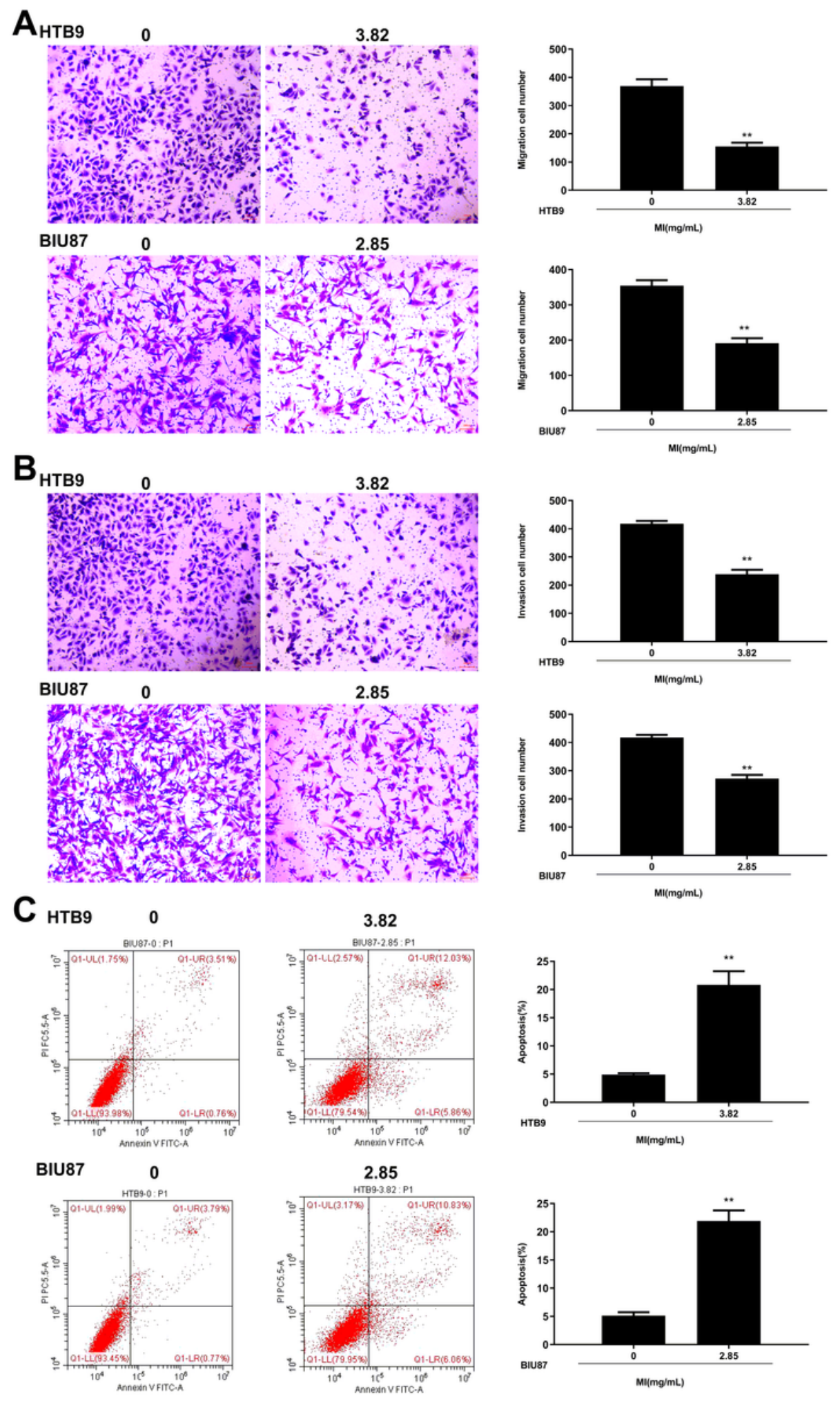

Figure 4

Effect of MI on invasion, migration and apoptosis of bladder cancer cells in vitro. HTB9 were treated with $3.82 \mathrm{mg} / \mathrm{mL}$ and BIU87 cells were treated with $2.85 \mathrm{mg} / \mathrm{mL}$. (A and $B$ ) The migration $(A)$ and invasion (B) capacity of HTB9 and BIU87 cells was evaluated by transwell assay. (C) The apoptosis rate of HTB9 and BIU87 cells was evaluated by flow cytometry. $N=6, * \star P<0.01$. 

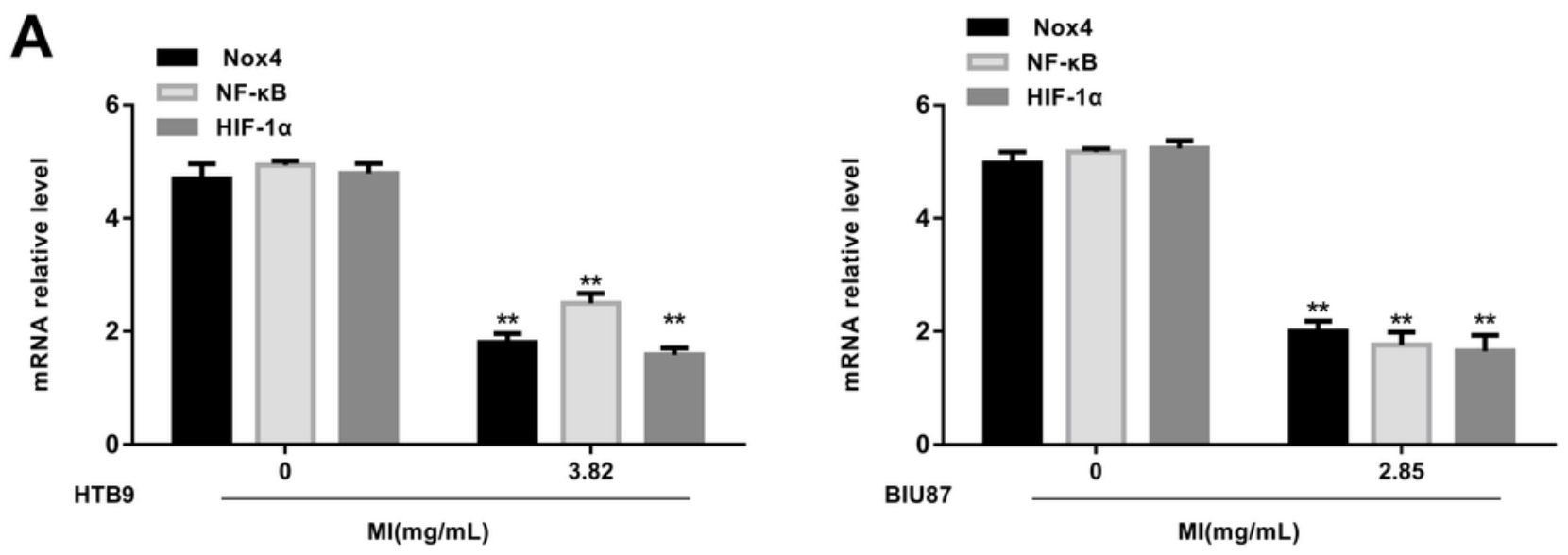

B
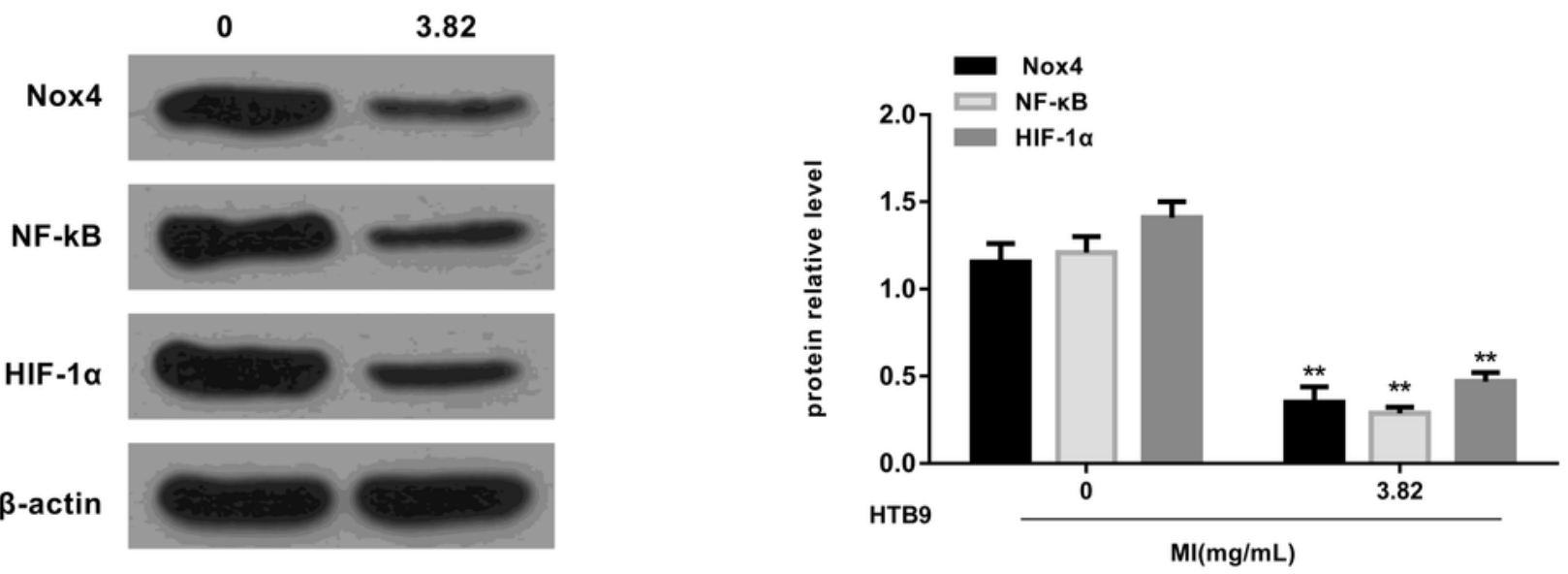

C
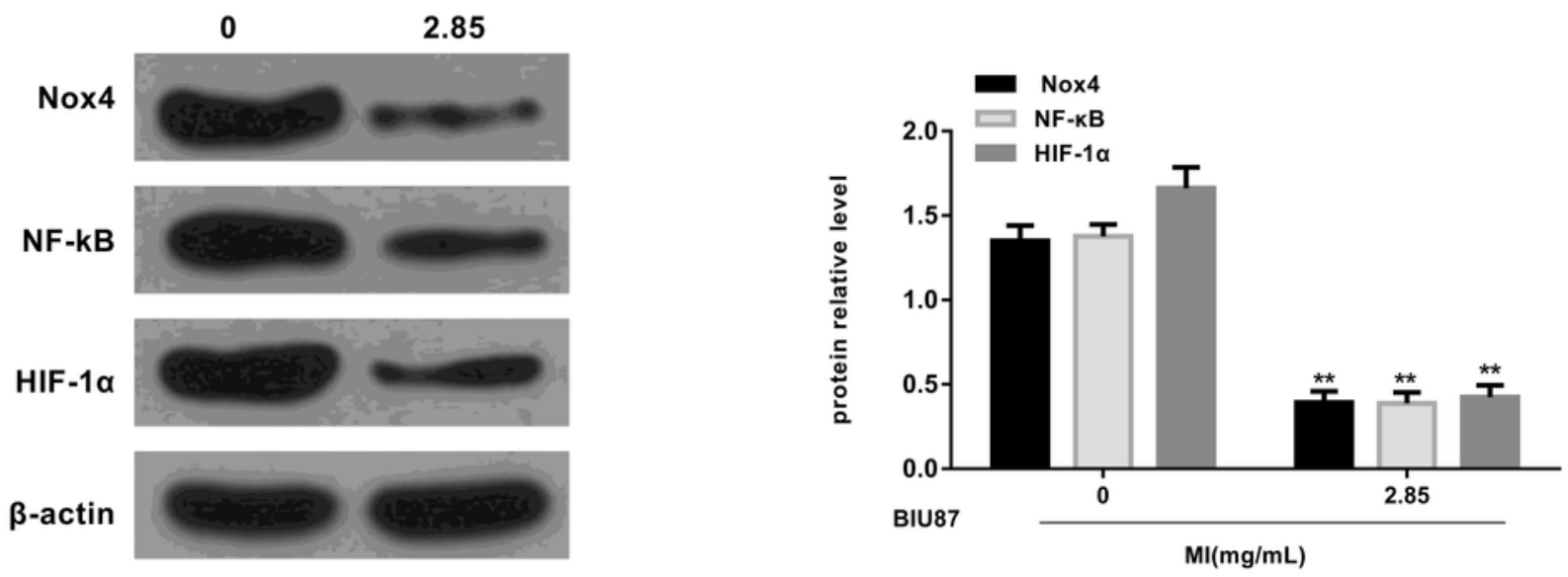

Figure 5

Effect of MI on invasion, migration and apoptosis of bladder cancer cells in vitro. HTB9 were treated with $3.82 \mathrm{mg} / \mathrm{mL}$ and BIU87 cells were treated with $2.85 \mathrm{mg} / \mathrm{mL}$. (A and $B$ ) The migration $(A)$ and invasion (B) capacity of HTB9 and BIU87 cells was evaluated by transwell assay. (C) The apoptosis rate of HTB9 and BIU87 cells was evaluated by flow cytometry. $N=6, * \star P<0.01$. 
A

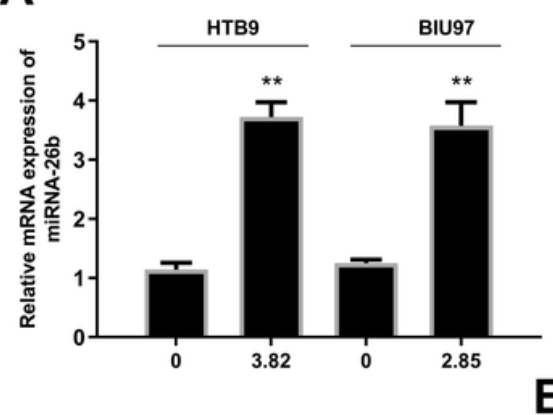

D

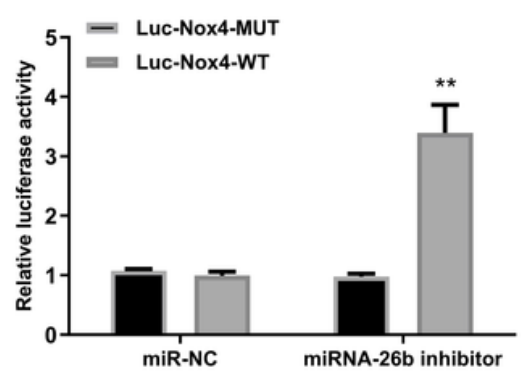

$\mathbf{E}$
B

miR-26b-5p UUCAAGUAAUUCAGGAUAGGU

$::$

Nox 4

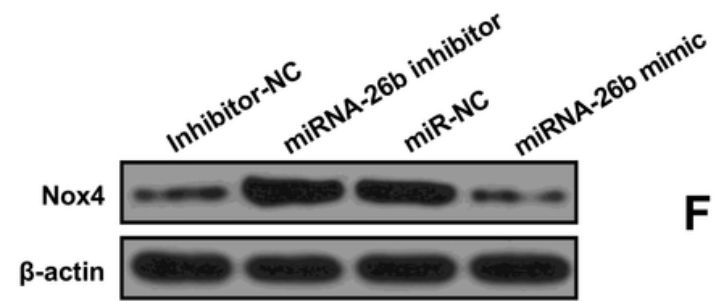

$\mathbf{F}$

C
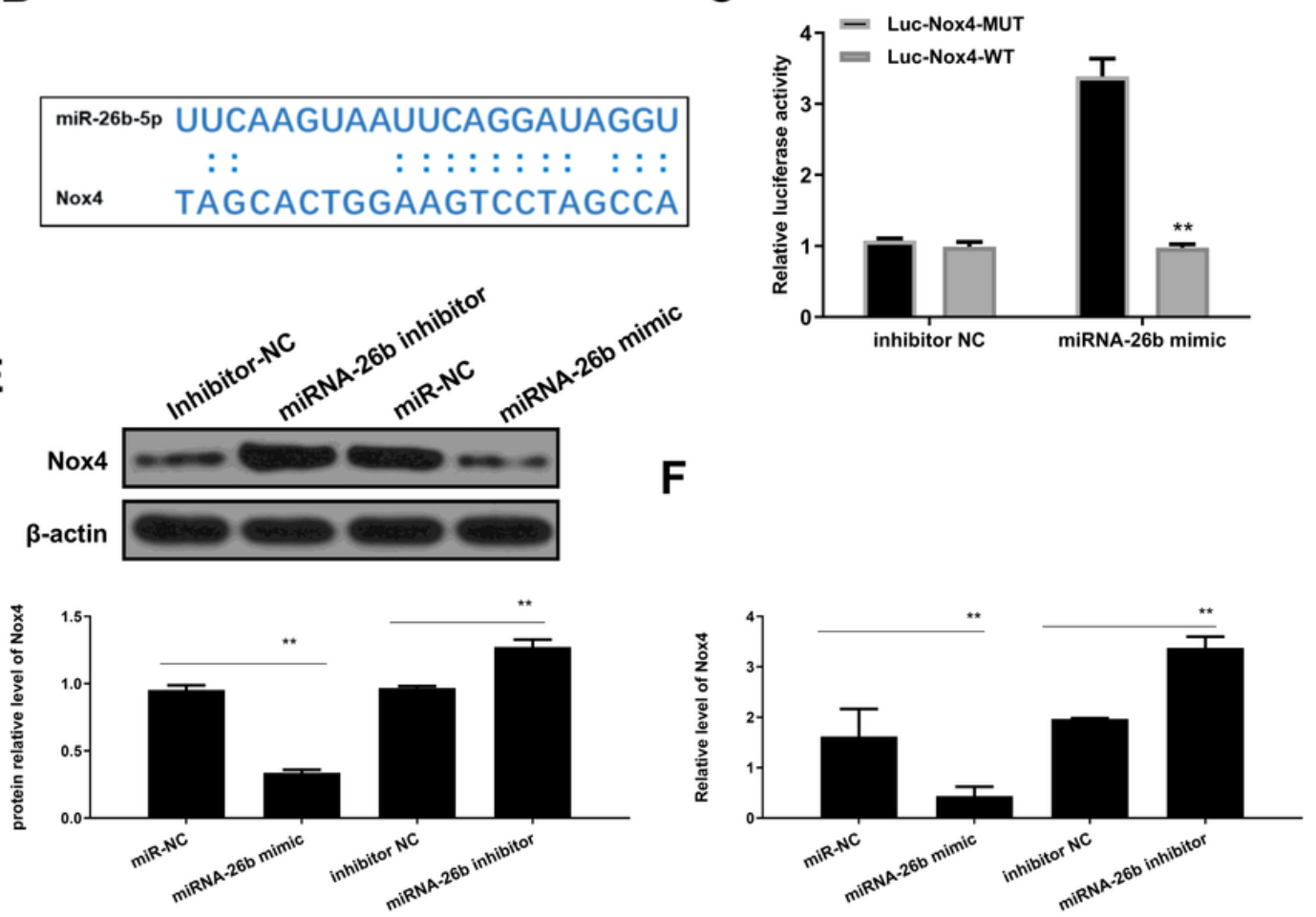

Figure 6

Nox4 was a target of miR-26b. (A) HTB9 were treated with $3.82 \mathrm{mg} / \mathrm{mL}$ and BIU87 cells were treated with $2.85 \mathrm{mg} / \mathrm{mL}$. The mRNA level of miR-26b was evaluated by qRT-PCR. (B) The interaction between miR-26b and Nox4 was predicted by Targetscan. (C and D) HTB9 cells were co-transfected with luciferase reporter plasmids containing WT or MUT Nox4 and miR-26b mimics/miR/NC (C), or miR-26b inhibitor/inhibitor NC (D), and the relative luciferase activity was detected by dual luciferase reporter system. (E) HTB9 cells were co-transfected with miR-26b mimics, miR-NC, miR-26 inhibitor, inhibitor NC, and the protein level of Nox4 was evaluated by western blot. $N=6, * * P<0.01$. Full-length blots/gels are presented in Supplementary Figure 3. 
A

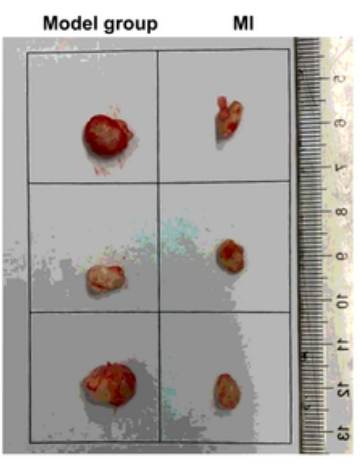

D

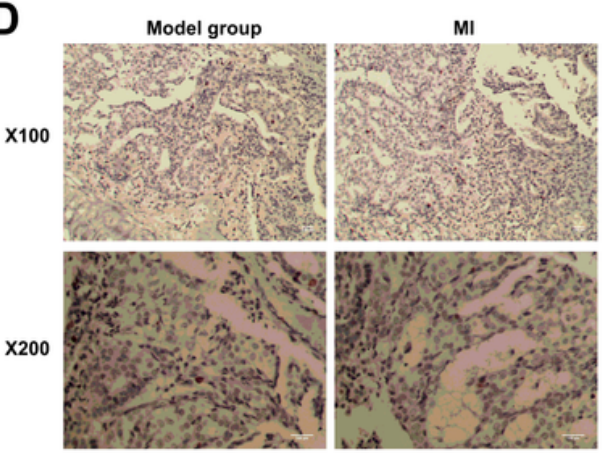

B

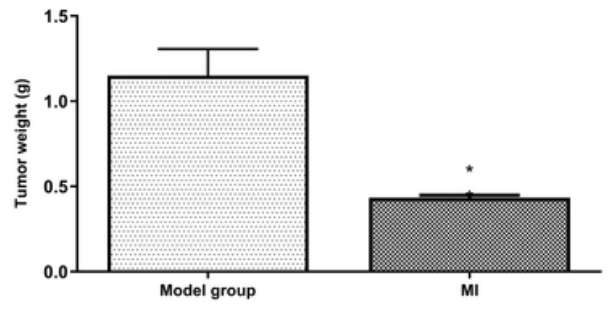

E

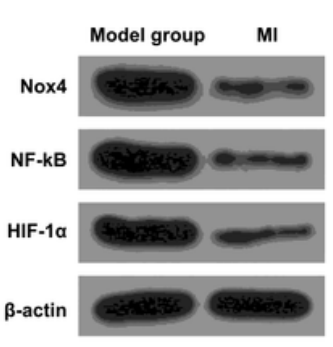

C
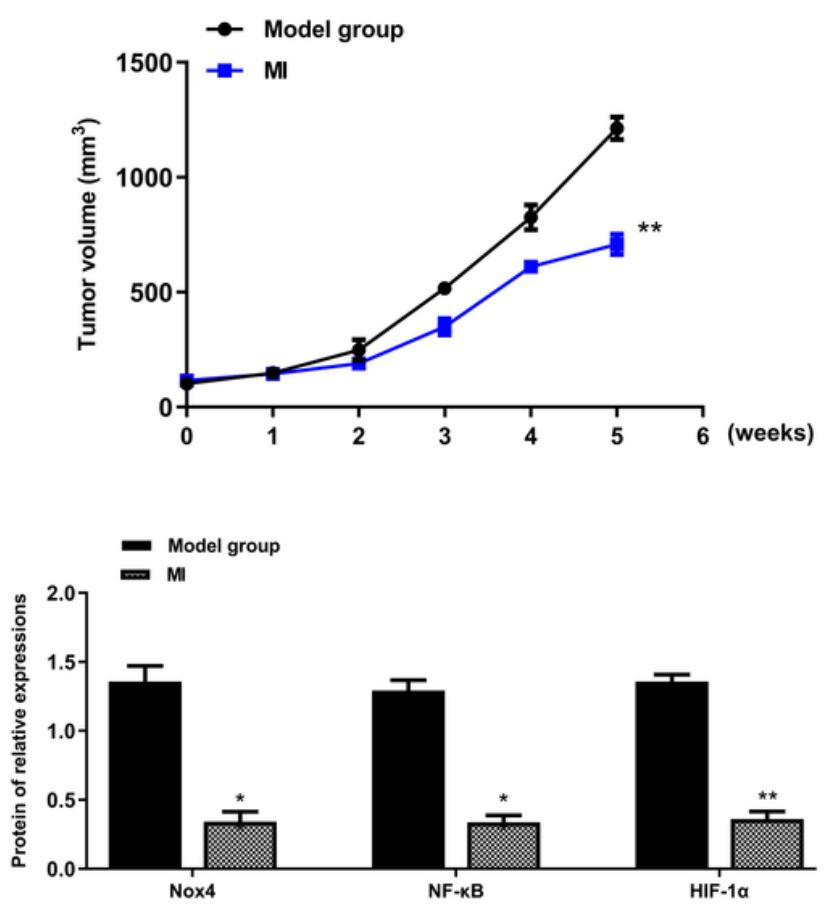

Figure 7

MI efficiently repressed the progression of bladder cancer in vivo. (A) The representative images of xenograft tumors $(n=8)$. (B) The tumor weight was evaluated at the 11th day $(n=8)$. (C) The tumor volume was evaluated every one week for 5 weeks $(n=8)$. (D) The Ki-67 staining of xenograft tumors $(n=$ 8). $\times 100 / \times 100$. (E) The protein level of Nox4, NF-KB and HIF-1 $a$ in tumor from different groups was evaluated by western blot $(n=6) .{ }^{* *} P<0.01$. Full-length blots/gels are presented in Supplementary Figure 4.

\section{Supplementary Files}

This is a list of supplementary files associated with this preprint. Click to download.

- originalwesternblot.docx 